\title{
Effectiveness of Isosorbide Mononitrate vs Prostaglandin E2 Gel for Cervical Ripening: A Study
}

\author{
Mayuri S Dixi ${ }^{1}$, Savita A Somalwar ${ }^{2}$, Ganesh R Tathe $^{3}$
}

\begin{abstract}
Background: Till date, search is going on for an ideal agent that can lead to cervical ripening and induction of labor and that is safe for mother and fetus. Isosorbide mononitrate (IMN) is an agent that is also used for preinduction cervical ripening but few studies are done with this drug and hence this study was carried out.

Aims and objectives: To study efficacy of IMN and PGE2 gel for preinduction cervical ripening and to study side effects of both drugs.

Materials and methods: It was a randomized controlled trial. Participants were selected according to the selection criteria. Group I included 100 participants in whom tab IMN was used. Group II included 100 participants in whom PGE2 gel was used. Outcome measures assessed were age, parity, gestational age, indication for induction of labor, assessment of modified Bishop's score (MBS) at 0 and 24 hours, change in MBS, and drug-related side effects. Statistical analysis was done.

Results: Mean age, parity, and mean gestational age were comparable in both groups. Postdatism and preeclampsia were indications for induction in both groups. Modified Bishop's score at 0 hour was comparable in both groups. Change in the MBS at 24 hours was $2.91 \pm 1.34$ in group I and $4.52 \pm 2.22$ in group II. Drug-related side effects were more in group I than in group II.

Conclusion: PGE2 gel was more effective for cervical ripening as compared to IMN. Isosorbide mononitrate leads to more side effects.

Keywords: Cervical ripening, Isosorbide mononitrate, Modified Bishop's score, Preinduction cervical ripening, Prostaglandin E2 gel.

Journal of South Asian Federation of Obstetrics and Gynaecology (2019): 10.5005/jp-journals-10006-1712
\end{abstract}

\section{INTRODUCTION}

The purpose of antenatal care is delivery of a healthy baby from a healthy mother. The aim of modern obstetrics is to improve the safety of the mother and the fetus both during the antenatal period and parturition. Stimulation of contractions before the spontaneous onset of labor, with or without ruptured membranes, is induction of labor. ${ }^{1}$ The purpose of the induction of labor is to have a vaginal delivery at term safely and also to ensure birth of a healthy fetus, with minimal maternal and fetal morbidity and mortality.

Labor is said to be a natural physiological process, but in few women labor does not occur spontaneously and need induction. In $20-30 \%$ of all pregnancies in the world, labor is induced. ${ }^{2}$ Cervical priming or cervical ripening is an important factor before induction, which determines the success of induction. Ripening of cervix is due to cascade of synchronized events causing spontaneous labor and vaginal delivery.

Cervical ripening is quite effective by prostaglandins but they have a high incidence of hyperstimulation and tachysystole, which may compromise the fetus. An ideal cervical ripening agent is the one that ripens the cervix without causing any harm to the mother and the fetus.

Nitric oxide (NO) donors such as isosorbide mononitrate (IMN) and glyceryl trinitrate (GTN) induce cervical ripening. Nitric oxide acts by rearranging cervical collagen and ground substance and softens the cervix. The inducible nitric oxide synthase (iNOS) present in the human cervix during postpartum, probably induced by cytokines, may be involved in the natural process of cervical ripening in humans. Also the hypothesis that NO is involved in the process of ripening of the cervix is supported by the increased expression of nitric oxide synthase (NOS) isoforms in late pregnancy. There are limited studies on NO donors for cervical ripening. Isosorbide mononitrate is one such agent that has been studied in

\begin{abstract}
1,2Department of Obstetrics and Gynecology, NKP Salve Institute of Medical Sciences and Research and Lata Mangeshkar Hospital, Nagpur, Maharashtra, India

${ }^{3}$ Department of Community Medicine, NKP Salve Institute of Medical Sciences and Research and Lata Mangeshkar Hospital, Nagpur, Maharashtra, India

Corresponding Author: Savita A Somalwar, Department of Obstetrics and Gynecology, NKP Salve Institute of Medical Sciences and Research and Lata Mangeshkar Hospital, Nagpur, Maharashtra, India, Phone: +919158920941, e-mail: somalwar.sa@gmail.com

How to cite this article: Dixit MS, Somalwar SA, Tathe GR. Effectiveness of Isosorbide Mononitrate vs Prostaglandin E2 Gel for Cervical Ripening: A Study. J South Asian Feder Obst Gynae 2019;11(5):288-291.

Source of support: Nil

Conflict of interest: None
\end{abstract}

the outpatient setting but there are conflicting results. More studies are required to prove its usefulness for cervical priming, especially in low-resource setups where cost does matter.

\section{Aims and Objectives}

- To study effectiveness of IMN vs prostaglandin E2 (PGE2) gel for cervical ripening.

- To study the side effects of IMN and PGE2.

\section{Materials and Methods}

The present study was a randomized controlled trial carried over a period of 2 years from December 2015 to November 2017 after 
approval of the Institutional Ethical Committee. Pregnant women with unripe cervix requiring induction of labor were enrolled in this study as per the inclusion and exclusion criteria. The inclusion criteria were all singleton pregnancies of gestational age (GA) $>37$ weeks with modified Bishop's score (MBS) $<6$, intact membranes, cephalic presentation, adequate pelvis, and reactive nonstress test. The exclusion criteria were women with antepartum hemorrhage, severe anemia, severe preeclampsia, eclampsia, heart disease, scar over the uterus [previous lower segment cesarean section (LSCS), classical cesarean section (CS), hysterotomy, myomectomy scar], grand multipara, fetal malpresentation, intrauterine growth restriction, intrauterine fetal death, asthma, hypotension, palpitations, any known allergy to receive IMN/PGE2, participants with glaucoma or raised intraocular pressure, and history of migraine.

Sample size was calculated by power analysis with the help of mean and standard deviation based on the previous study ${ }^{3}$ with power of $80 \%$ ( $\alpha=0.05$ and $\beta=0.2$ ). The total sample size of the present study was 200. A case record form was formulated and data collection of each case was done by filling the case record forms after taking informed consent of the participants. Group I included 100 participants in whom tab IMN (Monotrate, Sun Pharmaceutical Laboratories, East Sikkim, India) was given. Group II included 100 participants in whom PGE2 gel (Primigyn, Brassica Pharma Pvt. Ltd, Thane, India) was given.

In group I, tab IMN $40 \mathrm{mg}$ was inserted in the posterior fornix after soaking in normal saline at 0 and 12 hours after assessing MBS. Change in MBS was assessed at 24 hours.

In group II, dinoprostone gel $0.5 \mathrm{mg}$ was introduced intracervically after assessing MBS. Modified Bishop's score was assessed at 8 hours and 16 hours and dinoprostone gel was inserted if required. Change in MBS was assessed at 24 hours.

In all participants, maternal monitoring was done by one hourly pulse, blood pressure record. Fetal heart sounds were monitored every half an hourly by stethoscope. Per abdominal examination was done every half an hour to note the onset of uterine contractions and for fetal heart rate monitoring by a stethoscope. Symptoms such as pain in abdomen, leaking and bleeding per vaginum, and loss of fetal movements were noted. If there was any complaint of headache, nausea, and vomiting, they were noted. In both the groups, during labor, the participant's vital parameters (pulse, blood pressure, hydration, urine output) were monitored and per abdomen examination was done half hourly, giving special attention to fetal heart sounds and uterine activity. If a participant goes in labor, continuous fetal heart monitoring was done with the help of a cardiotocography machine and a partograph was maintained.

In all the participants, outcome measures assessed were age, parity, gestational age, indication for induction of labor, assessment of MBS at 0 and 24 hours, change in MBS, and drug-related side effects. The statistical analysis was done with the help of the statistical software EPIINFO version 7.0. Results were graphically represented where deemed necessary. Graphical representation was done in MS Excel 2010. Quantitative data were presented with the help of mean and standard deviation. Comparison among the study group was done with the help of the Student's $t$ test and the Welch's test as per results of the normalcy test. Qualitative data were presented with the help of the frequency and percentage table. Association among the study groups was assessed with the help of the Chi-square test. The $p$ value less than 0.05 was taken significant.

\section{Results}

Mean age in group I was $24.79 \pm 3.22$ years and in group II was $24.57 \pm 3.02$ years. By using the $t$ test, the $p$ value was greater than 0.05 , which was not significant. Thus, both the groups were comparable with respect to the age of the participants.

Out of 100 participants in group I, 75\% were nulliparous while $20 \%$ were of parity 1 and $5 \%$ were of parity 2 . Out of 100 participants in group II, 74\% were nulliparous while $17 \%$ were of parity 1 and $9 \%$ were of parity 2 . By using the Chi-square test, $p=0.498$, which means there is no statistical significance between the distribution of parity in both the groups. The mean gestation age in group I was $40.16 \pm 0.57$ weeks, while in group II it was $40.24 \pm 0.44$ weeks

By using the $t$ test, the $p$ value came out to be 0.2680 . Thus there was no significant difference between the gestational ages in both the groups. Thus, both the groups were comparable with respect to the gestational age.

In group I, indication for induction of labor was postdatism in $80 \%$ and mild preeclampsia was present in $20 \%$, whereas in group II, indication for induction of labor was postdatism in $77 \%$ and mild preeclampsia in $23 \%$.

There was no significant difference in both the groups with respect to indication for induction as the $p$ value is greater than 0.05 by the Chi-square test (Fig. 1).

The mean MBS at 0 hour in group I was $3.13 \pm 0.72$, while in group II it was $3.17 \pm 1.15$. By using the $t$ test, the $p$ value was 0.768 , showing that there was no statistical significance between the mean MBS at 0 hour in both the groups (Table 1).

Modified Bishop's score at 24 hours in group I was $6.04 \pm 1.11$ and in group II was $7.27 \pm 1.77$. A total of 36 participants in group II had delivered before 24 hours. The $p$ value by the Welch's $t$ test was 0.001 , showing statistically significant increase in MBS at 24 hours in group II than in group I (Table 2).

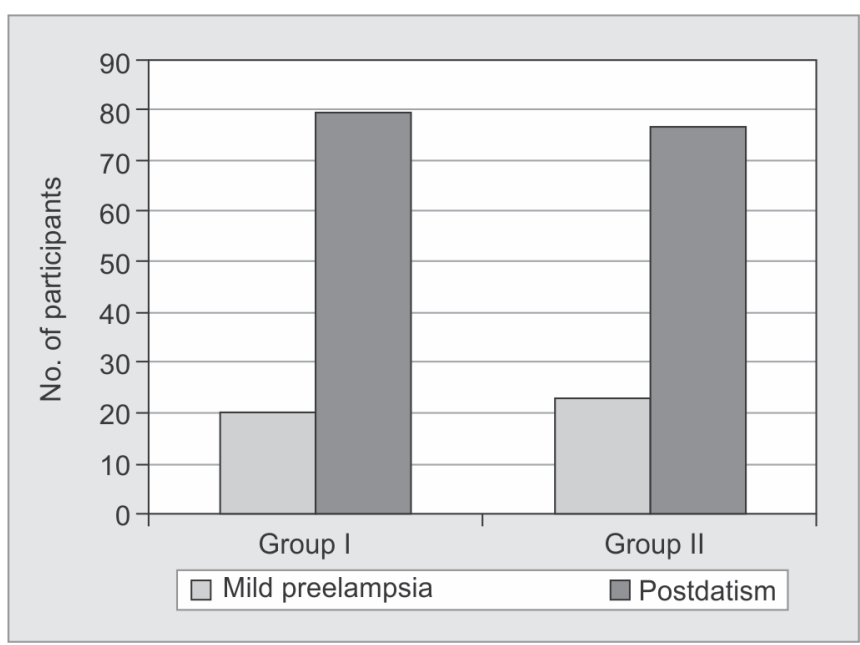

Fig. 1: Bar diagram showing indication for induction

Table 1: Modified Bishop's score at 0 hour $(n=100)$

\begin{tabular}{lllll}
\hline & $\begin{array}{l}\text { Number of } \\
\text { participants }\end{array}$ & $\begin{array}{l}\text { Preripening } \\
\text { MBS (mean } \pm S D)\end{array}$ & t test value & $p$ value \\
\hline Group I & 100 & $3.13 \pm 0.72$ & 0.2948 & 0.768 \\
Group II & 100 & $3.17 \pm 1.15$ & & \\
\hline
\end{tabular}


Table 2: Modified Bishop's score at 24 hours

\begin{tabular}{lllll}
\hline Group & $\begin{array}{l}\text { Number of } \\
\text { participants }\end{array}$ & $\begin{array}{l}\text { Postripening MBS } \\
(\text { mean } \pm \text { SD) }\end{array}$ & $\begin{array}{l}\text { Welch's t test } \\
\text { value }\end{array}$ & p value \\
\hline Group I & 100 & $6.04 \pm 1.11$ & 3.528 & 0.001 \\
Group II & 64 & $7.27 \pm 1.77$ & & \\
\hline
\end{tabular}

Table 3: Change in modified Bishop's score at 24 hours

\begin{tabular}{lllll}
\hline Group & $\begin{array}{l}\text { Number of } \\
\text { participants }\end{array}$ & $\begin{array}{l}\text { Change in MBS } \\
(\text { mean } \pm \text { SD) }\end{array}$ & $\begin{array}{l}\text { Welch's t test } \\
\text { value }\end{array}$ & p value \\
\hline Group I & 100 & $2.91 \pm 1.34$ & 0.064 & 0.0000001 \\
Group II & 64 & $4.52 \pm 2.22$ & & \\
\hline
\end{tabular}

Table 4: Different types of drug-related side effects

\begin{tabular}{lcccc}
\hline $\begin{array}{l}\text { Drug-related } \\
\text { complications }\end{array}$ & Group I(\%) & Group II (\%) & Chi-square & p value \\
\hline Gl symptoms & $0(0)$ & $6(6)$ & 6.18 & 0.012 \\
Headache & $17(17)$ & $0(0)$ & 18.57 & $<0.0001$ \\
Tachycardia & $3(3)$ & $0(0)$ & 3.04 & 0.12 \\
No complications & $80(80)$ & $94(94)$ & & \\
Total & $100(100)$ & $100(100)$ & & \\
\hline
\end{tabular}

Change in the MBS at 24 hours was $2.91 \pm 1.34$ in group I and $4.52 \pm 2.22$ in group II. By the Welch's $t$ test, the $p$ value was 0.0000001 , which shows statistically significant increase in change in MBS at 24 hours in group II than in group I. A total of 36 participants in group II had delivered before 24 hours (Table 3 ).

Headache was the most common side effect in group I-17 (17\%), and Gl symptoms (nausea, vomiting) were most common in group II-6 (6\%). Tachycardia was present in $3(3 \%)$ participants in group I. There was significant difference between incidence of headache and $\mathrm{Gl}$ symptoms in both the groups ( $p$ value $<0.05$ in both the groups). There was no complication of tachysystole in both the groups. Overall, drug-related side effects were more in the participants of group I than in group II (Table 4).

\section{Discussion}

The aim of the induction of labor is to have safe vaginal delivery at term and to ensure birth of a healthy fetus with minimal maternal and fetal morbidity and mortality. There are only few studies comparing IMN and PGE2 gel as an agent for cervical ripening.

In the present study, mean age of participants was 24.79 years in the IMN group, while in the PGE2 group, mean age of participants was 24.57 years.

In a study conducted by Agarwal et al., ${ }^{3}$ the mean age group was 23.4 years in the IMN group and 23.57 years in the PGE2 group, which closely correlates with our study. Also, the findings in Duhan et al., ${ }^{4}$ Dave et al., ${ }^{5}$ Yazdizadeh et al., ${ }^{6}$ and Krishnamurthy et al. ${ }^{7}$ were comparable with our study.

Majority participants in the present study were nulliparous in both the groups, $75 \%$ in the IMN group and $74 \%$ in the PGE2 group. Only $25 \%$ were with parity $\geq 1$ in the IMN group and $26 \%$ in the PGE2 group. In the Agarwal et al. ${ }^{3}$ study, there was no significant difference paritywise in both the groups. In Dave et al. ${ }^{5}$ study, in the IMN group, $35.6 \%$ were nulliparous and $65.3 \%$ were with parity $\geq 1$.

In the present study, the mean gestation age was 40 weeks, which was comparable in both the groups. Our study correlated with Dave et al., ${ }^{5}$ Yazdizadeh et al., ${ }^{6}$ and Krishnamurthy et al. ${ }^{7}$ with respect to mean gestational age. In the present study, postdatism (80\% in IMN and $77 \%$ in PGE2 group) was the most common indication for induction followed by mild preeclampsia (20\% in IMN and $23 \%$ in PGE2 group).

In the study by Duhan et al., ${ }^{4}$ preeclampsia and postdatism were most common indications in both the groups ( $74 \%$ in the isosorbide dinitrate group and $74 \%$ in the PGE2 group). In the study by Dave et al., ${ }^{5}$ the indications for induction were postterm pregnancies, intrauterine growth restriction (IUGR), intrauterine death (IUD), hypertensive disorders, diabetes mellitus, and oligohydramnios.

Thus, as in the present study, postdatism was most common indication for induction of labor in Agarwal et al., ${ }^{3}$ Krishnamurthy et al., ${ }^{7}$ Collingham et al., ${ }^{8}$ and Duhan et al. ${ }^{4}$ In our study, mean MBS at 0 hour was 3.13 in the IMN group while in PGE2 it was 3.17. Both the groups were comparable with respect to preripening MBS. Our study closely correlated with that of Yazdizadeh et al. ${ }^{6}$ with respect to preripening MBS.

In the present study, change in MBS at 24 hours was statistically more in the PGE2 group than the IMN group ( $2.91 \pm 1.34$ in the IMN group and $4.52 \pm 2.22$ in the PGE2 group). Thus, our study results closely correlated with that of Agarwal et al. ${ }^{3}$ study where the postripening change in MBS was statistically more in the PGE2 group than in the IMN group. In the present study, headache was $17 \%$ in the IMN group and $0 \%$ in the PGE2 group while gastrointestinal complaints were present in $0 \%$ in the IMN group and $6 \%$ in the PGE2 group. Tachycardia was present in 3\% in the IMN group and $0 \%$ in the PGE2 group. There was no uterine tachysystole in either of the groups.

In the present study, headache was major drug-related complication in IMN group. Similarly, headache was statistically more common in the IMN group than the PGE2 group in the studies done by Agarwal et al., ${ }^{3}$ Pallavi, ${ }^{9}$ Duhan et al., ${ }^{4}$ and Mukhtar et al. ${ }^{10}$ In the present study, uterine tachysystole was not present in either of the groups, which correlated with the study by Mukhtar et al. ${ }^{10}$ Uterine hyperstimulation was not found in either of the groups in the present studies but was present in the study done by Agarwal et al. ${ }^{3}$ and Duhan et al. ${ }^{4}$ in the PGE2 group and not in the IMN group.

\section{Conclusion}

The present study concludes that PGE2 gel is more effective for cervical ripening as compared to IMN. Isosorbide mononitrate leads to cervical ripening and change in MBS, but it is less as compared to PGE2 gel. Also, IMN does not lead to induction of labor alone as that of PGE2 gel. The present study also concludes that the drugrelated side effects are more in the IMN group as compared with the PGE2 group. Many new drugs are emerging for cervical ripening and induction of labor but at present, no drug is proven to be the safest drug for cervical ripening and induction of labor.

\section{Acknowledgments}

We acknowledge the cooperation of the Professor and Head of the Department of Obstetrics and Gynaecology, Dr Sulabha Joshi, and Unit Incharges, Dr Anjali Kawthalkar and Dr Anuja Bhalerao.

\section{References}

1. Cunningham $F$, Leveno $K$, Bloom $S$, et al. Induction and augmentation of labor. Williams Obstetrics, 24th ed., ch. 26, USA: McGraw Hills Education; 2014. p. 523. 
2. Thorbiörnson A, Vladic T, Stjernholm Y. Labor induction in primiparous women and women with an unripe cervix. J Pregnancy Child Health 2016;3(3):1-5.

3. Agarwal K, Batra A, Batra A, et al. Randomized comparison of isosorbide mononitrate and PGE2 gel for cervical ripening at term including high risk pregnancy. Int J Reprod Med 2014;2014:147274. DOI: 10.1155/2014/147274.

4. Duhan N, Hooda M, Sen J. Intracervical dinoprostone versus vaginal isosorbide dinitrate for cervical ripening at term. Indian J Fund Appl Life Sci 2012;2(2):269-275.

5. Dave A, Nigam P, Maru L. Isosorbide mononitrate a nitric oxide donor: a study of its efficacy and safety as an agent for cervical ripening. J Obstet Gynaecol India 2015;65(3):162-166. DOI: 10.1007/s13224-0140577-5.

6. Yazdizadeh $\mathrm{H}$, Abedi $\mathrm{P}$, Angali K. The impact of isosorbide mononitrate on cervical ripening and labor induction in primiparous women with term pregnancy: a double-blind, randomized, controlled trial. Iran J Nurs Midwifery Res 2013;18(3):246-250.

7. Krishnamurthy R, Pallavee P, Ghose S. Evaluation of isosorbide mononitrate for preinduction of cervical ripening: a randomized placebo-controlled trial. J Family Reprod Health 2015;9(2): 75-81.

8. Collingham JP, Fuh KC, Caughey AB, et al. Oral misoprostol and vaginal isosorbide mononitrate for labor induction: a randomized controlled trial. Obstet Gynecol 2010;116(1):121-126. DOI: 10.1097/ AOG.0b013e3181e408f2.

9. Pallavi RK, D'Souza L, Nayak S, et al. Isosorbide mononitrate versus dinoprostone gel for cervical ripening at term: maternal and fetal outcome. Int J Pharm Sci Res 2013;4(9):121-124.

10. Mukhtar A, Kazmi F, Rehana F. Comparison of vaginal isosorbide mononitrate with prostaglandin E2 for pre-induction cervical ripening at term. J Rawalpindi Med Coll 2013;17(1):110-112. 